\title{
Internet addiction and mental well-being among secondary school students in a Malaysian district: A cross-sectional survey
}

\author{
Luke Sy-Cherng Woon ${ }^{1}$ \\ ${ }^{1} \mathrm{MD}$, DrPsych, Department of Psychiatry, University Kebangsaan Malaysia Medical Centre,Kuala Lumpur, Malaysia \\ https://orcid.org/0000-0002-8216-0694
}

\section{TO THE EDITOR}

The number of internet users is steadily rising in Malaysia, with students spending the longest time online at three hours per day (1). Worryingly, recent National Health and Morbidity Surveys (NHMSs) have shown high prevalence of internet addiction among adolescent participants (2), besides elevated levels of depression, anxiety and stress (3).

A number of studies have examined internet addiction and mental well-being among adolescents. They revealed a general pattern of correlation between internet addiction and poor mental health $(4,5,6,7)$. For example, a study among adolescents in Croatia and Germany using the Internet Addiction Test (IAT) and the Short Form (36-item) Health Survey (SF-36) found significant correlation between poor mental health and quality of life and the level of internet addiction (6). Similar, internet addiction was also associated with poorer mental health among Japanese adolescents (7). However, such research data is scarce in Malaysia.

A cross-sectional survey was conducted which aimed to determine the prevalence of internet addiction, depression, anxiety and stress in a sample of secondary school students in Bentong, a rural district in Pahang state of Peninsular Malaysia. Secondarily, we explored the associations between internet addiction and depression, anxiety and stress.

In conjunction with the World Mental Health Day 2018, a half-day seminar was jointly organised at a local school by the psychiatric unit of Bentong Hospital and the district education office, with invitations sent out to all 18 secondary schools in the district. Up to eight conveniently selected students were sent by each school to take part in the event. During the programme, a talk on internet addiction was delivered. Two screening questionnaires, the Malay-version Depression, Anxiety and Stress-21 Scale (DASS-21) and the Malay-version Internet Addiction Test (MVIAT) were distributed to all participants and collected from them.

The 20-item IAT is among the most commonly used instruments for the assessment of internet addiction. It measures internet addiction using a 5point Likert scale (from $1=$ rarely, to $5=$ always) with the maximum score of 100 (8). Internet addiction is defined as a score of 43 or more. The MVIAT has shown good internal consistency (Cronbach's $\mathrm{a}=0.91$ ), parallel reliability (intraclass correlation coefficient $=0.88$ ) and concurrent validity with the Compulsive Internet Use Scale (Pearson's correlation coefficient $=0.84)(9)$.

The 21-Item DASS (DASS-21) is a shorter version of the original DASS with 42 items. It is a set of self-reported questionnaire with three subscales measuring depression, anxiety and stress over the past week on a Likert scale of 0 to 3 (10). The cutoff points for depression, anxiety and stress scores are 13, 9, and 18, respectively. The Malay-version has high Cronbach's alpha values of $0.75,0.74$ and 0.79 respectively for depression, anxiety and stress, besides demonstrating good construct validity (11).

Additionally, basic demographic data, including 
Internet addiction and mental well-being among secondary school students in a Malaysian district: A cross-sectional survey

age, gender, ethnicity and school of the participants was also collected.

Data were analysed using the SPSS version 20.0 software. Rates of internet addiction, depression, anxiety and stress among participants were calculated. Pearson's correlation coefficients and Chisquare tests were used to measure correlations and to compare dichotomous outcomes, respectively. Multivariate analysis of variance (MANOVA) was conducted to explore interactions between internet addiction, depression, anxiety, and stress. All tests were two-tailed with the significance level set at 0.05 .

There were 125 participants in the survey (Age: 1417 years). Male students consisted $50.4 \%$ of the sample; $86.4 \%$ were Malays. Internet addiction was identified in $45.6 \%$. The proportions of participants with depression, anxiety and stress were $25.6 \%, 47.2 \%$, and $20.0 \%$ respectively. There was no gender or ethnic difference in the internet addiction rate.

IAT scores showed moderate-to-strong correlations with depression, anxiety and stress scores (Table 1). Internet-addicted students were more likely to be depressed ( $\mathrm{X} 2=9.292, \mathrm{p}=0.002)$, anxious $\left(X^{2}=13.190, \quad \mathrm{p}<0.001\right)$, and stressed $(\mathrm{X} 2=6.321, \mathrm{p}=0.012)$. In MANOVA, there was a statistically significant difference in depression, anxiety and stress scores based on internet addiction status, $\mathrm{F}(3,121)=9.14, \mathrm{p}<0.0005$; Wilk's $\Lambda=0.815$, partial $\eta 2=0.19$. Internet addiction had a statistically significant effect on depression scores, $(\mathrm{F}(1,123)=12.39 ; \mathrm{p}<0.0005 ;$ partial $\eta 2=0.10)$, anxiety scores $(\mathrm{F}(1,123)=19.19 ; \mathrm{p}<0.0005$; partial $\eta 2=0.14)$, and stress scores $(F(1,123)=26.75$; $\mathrm{p}<0.0005 ; \eta 2=0.18)$.

Internet addiction rate in this survey was higher than the national $(29.0 \%)$ and state $(30.7 \%)$ figures in the Malaysian national survey (2). Depression and anxiety prevalence rates were comparable with the national findings, but stress prevalence was about twice higher (3).

This study demonstrated clear linear correlations between the severity of internet addiction and the level of depression, anxiety and stress, confirming a negative association with general mental health. Firstly, it confirmed similar findings from recent Malaysian studies among medical students (12) and secondary school students in the Metropolitan Kuala Lumpur (13). It also corroborated with recent findings among adolescents from other countries such as Japan (7) and Iran (14).

While longitudinal association between psychological distress and internet addiction has been demonstrated among adolescents (15), the directional association between psychological distress and internet addiction is not yet clear. Some authors have postulated that mental ill-health could be the underlying factor among people with internet addiction whose usage the Internet acted as a way of to avoid unpleasant emotional experiences, including anxious feelings, stress and solitude (16).

On the other hand, Internet use in excess can contribute to greater social isolation, which in turn can result in psychological symptoms such as depression (14). Additionally, how different applications of the internet (e.g. social media and internet gaming) may influence symptoms, remain to be investigated.

Despite the limitations to this study, including single study site, small sample size and potential bias due to convenient sampling, there was evidence that internet addiction was common among sec-

Table 1. Descriptive statistics and correlations for internet addiction, depression, anxiety, and stress.

\begin{tabular}{lllll}
\hline Variable & Internet addiction & Stress & Anxiety & Depression \\
\hline Internet addiction & 1 & & & \\
Stress & $.630^{* *}$ & 1 & & \\
Anxiety & $.605^{* *}$ & $.789^{* *}$ & 1 & \\
Depression & $.514^{* *}$ & $.769^{* *}$ & $.731^{* *}$ & 1 \\
M & 43.42 & 6.32 & 4.59 & 4.52 \\
SD & 12.433 & 4.035 & 3.391 & 4.284 \\
\hline$* * p<0.01$ & & & &
\end{tabular}


ondary school students in a rural Malaysian district, and it was strongly associated with mental illhealth. Such findings call for further investigations into relevant clinical factors and timely implementation of effective interventions for internet addiction among adolescents.

\section{Acknowledgments}

The author would like to express his appreciation and gratitude to Dr Tiong Chea Ping, Dr Sharon Kaur Bhart and Dr Siti Umi Fairuz Azmi for their assistance in conducting the study and to the
Bentong District Education Office for its support in conducting this study.

\section{Funding}

This research did not receive any funding.

Correspondence address: MD, Luke Sy-Cherng Woon, Universiti Kebangsaan Malaysia Medical Centre, Jalan Yaacob Latif, Bandar Tun Razak 56000 Cheras, Kuala Lumpur, Malaysia lukewoon@gmail.com

\section{REFERENCES}

1. Malaysian Communications and Multimedia Commission. Internet Users Survey 2016: Statistical Brief No. 20. Malaysia: Malaysian Communications and Multimedia Commission, 2016.

2. Institute for Public Health. National Health and Morbidity Survey 2017 (NHMS 2017): Adolescent Health Survey. Malaysia: Institute for Public Health, Ministry of Health Malaysia, 2017a.

3. Institute for Public Health. National Health and Morbidity Survey 2017 (NHMS 2017): Adolescent Mental Health (DASS21). Malaysia: Institute for Public Health, Ministry of Health Malaysia, 2017b.

4. Kawabe K, Horiuchi F, Ochi M, Oka Y, Ueno S. Internet addiction: Prevalence and relation with mental states in adolescents. Psychiatry Clin Neurosci 2016; 70:405-412. doi: 10.1111/pcn.12402

5. Gholamian B, Shahnazi H, Hassanzadeh A. The prevalence of internet addiction and its association with depression, anxiety, and stress, among high-school students. Int J Pediatr 2017; 5:4763-4770. doi: 10.22038/IJP.2017.22516.1883

6. Karacic S, Oreskovic S. Internet addiction and mental health status of adolescents in Croatia and Germany. Psychiatr Danub 2017; 29:313-321. doi: 10.24869/psyd.2017.313

7. Kawabe K, Horiuchi F, Ochi M, Oka Y, Ueno S. Internet addiction: Prevalence and relation with mental states in adolescents. Psychiatry Clin Neurosci 2016; 70: 405-412. doi: 10.1111/pen.12402

8. Young KS. Internet addiction: The emergence of a new clinical disorder. Cyberpsychol Behav 1998; 1:237-244. doi: 10.1089/cpb.1998.1.237

9. Ng CG, Isa SM, Hashim AH, Pillai SK, Harbajan Singh MK Validity of the Malay Version of Internet Addiction Test (MVIAT): A Study on a group of medical students in Malaysia Asia Pac J Public Health 2015: 27:NP2210-9. doi: $10.1177 / 1010539512447808$

10. Lovibond PF, Lovibond SH. Manual for the depression, Anxiety and Stress Scales. Sydney: Psychology Foundation, 1995.

11. Musa R, Fadzil MA, Zain Z. Translation, validation and psy- chometric properties of Bahasa Malaysia version of the Depression Anxiety and Stress Scales (DASS). ASEAN J Psychiatry 2007; 8:82-89.

12. Ching SM, Awang H, Ramachandran V, Lim SMS, Wan Sulaiman WA, Foo YL, Yee A, Hoo F. Prevalence and factors associated with internet addiction among medical students - a cross-sectional study in Malaysia. Med J Malaysia 2017; 72:7-11.

13. Abdul Aziz M, Wan Ismail WS, Bahar N, Mahadevan R, Azhar Shah S. Internet addiction among secondary school students in Klang Valley, Malaysia: What is the association with depressive symptoms, anxiety symptoms, and self-esteem? Int Med J Malaysia 2018; 17:17-26.

14. Ostovar S, Allahyar N, Aminpoor H, Moafian F, Md Nor M, Griffiths MD. Int J Ment Health Addiction 2016; 14:257-267. doi: 10.1007/s11469-015-9628-0

15. Choi JS, Park SM, Roh MS, Lee JY, Park CB, Hwang JY, Gwang AR, Jung HY. Dysfunctional inhibitory control and impulsivity in Internet addiction. Psychiatry Res 2014; 215:4248. doi: 10.1016/j.psychres.2013.12.001.

16. Stavropoulos V, Gomez R, Steen E, Beard C, Liew L, Griffiths MD. The longitudinal association between anxiety and Internet addiction in adolescence: The moderating effect of classroom extraversion. J Behav Addict 2017; 6:237-247. doi: $10.1556 / 2006.6 .2017 .026$ 